\title{
A justa medida da sinalização
}

\author{
The right measurements for signs
}

Sinalização, design corporativo, legibilidade, veiculação de informação.

\begin{abstract}
O processo de criação e desenvolvimento de projetos de sinalização é amplo e envolve diversas variantes que não somente o design das placas e sua distribuição pelo espaço. A integração da sinalização com o ambiente, sua legibilidade e a relação entre sinalização e a identidade corporativa são aspectos a serem estudados e pré-determinados de forma a se encontrar a melhor solução, seja para um shopping ou um hospital.
\end{abstract}

Signs - corporate design - legibility - information bearing

The process for creating and developing signage projects is broad and involves different variants, not just the design of the sign itself and its placement and distribution. The integration between signs and the environment, their legibility and the relationship between signs and corporate identity are aspects to be studied and pre-determined in order to find the best solution, be it for a shopping mall or a hospital.

O congestionamento está infernal. Sintonizo uma rádio que só transmite informações sobre trânsito e espero ansioso, por instantes que parecem uma eternidade, até que o locutor me alimente com as informações que desejo ouvir: quais as causas daquela exasperante lentidão no local onde estou e o que me aguarda à frente. Neste caso até parecemos ganhar na loteria quando recebemos a informação desejada no tempo e espaço. Conceber, desenvolver e implementar projetos de sinalização é parecido com isso, só que ao contrário. Temos de nos antecipar às demandas dos usuários, oferecendo informação precisa que Ihes permita tomar decisões.

Parece óbvio, mas não custa repetir: sinalização é, essencialmente, um processo de veiculação de informações. Mas ao contrário de uma televisão, monitor, revista ou jornal, onde estão concentradas muitas informações ao simples folhear ou mesmo ao toque de um dedo, as informações contidas no projeto de sinalização estão distribuídas no espaço físico de um edifício ou área. Um exemplo bem prático: quando navegamos na internet, para mudar de assunto basta ativar a musculatura de um único dedo. Porém, num edifício cuja arquitetura desconhecemos, caso procuremos um prosaico sanitário ou a indicação de uma vaga para estacionar, temos de nos locomover fisicamente, procurando o dado necessário.

O objetivo primário é o de informar corretamente o usuário, para que ele tome sua decisão no menor espaço de tempo. E, se possível, antecipando suas demandas por informação. Parece complicado e é mesmo. Cada individuo é único em sua capacidade de leitura e entendimento. Ao mesmo tempo cada edifício também tem suas peculiaridades. Já a sinalização implantada deve atender a todos. Nessa equação surgem alguns outros componentes importantes: visibilidade, legibilidade, linguagem verbal - isto é, a qualidade do texto - e linguagem visual - isto é, os signos, cores, a tipografia e os padrões gráficos adotados num projeto.

$\mathrm{O}$ arquiteto Mies van der Rohe adotou a paradoxal expressão less is more para descrever um estilo de arquitetura minimalista, em que os elementos componentes devam ser limitados aos estritamente necessários e fundamentais para a concepção e funcionalidade do espaço projetado. O minimalismo não restringiu sua atuação à arquitetura e teve grande repercussão nas artes visuais e na música. Apesar de não adotarmos esse conceito como cláusula pétrea, procuramos seguir esse mantra nos projetos de sinalização, eliminando elementos que possam poluir o suporte da informação ou prejudicar sua legibilidade. Milton Glaser, em uma palestra para a Aiga 
em 2001, sugeriu nova expressão, ainda que genérica, para resumir melhor nossa constante busca de soluções em projetos de design: just enough is more.

Então, qual é essa justa medida em projetos de sinalização? Como um complexo quebracabeça, primeiramente temos que dispor de todas as peças necessárias para então proceder à sua montagem. $E$ as três peças chave desses projetos são: integração com o ambiente; relação entre sinalização e identidade corporativa; e legibilidade.

\section{Sinalização e arquitetura}

Uma das preocupações iniciais em nossos projetos de sinalização é a de não competir com a arquitetura e o próprio ambiente a ser sinalizado. Esta regra é fundamentada na premissa de que o projeto de sinalização tem como objetivo orientar os usuários da melhor e mais rápida maneira possível, sem a pretensão de definir ou delimitar espaços e sua utilização. A sinalização, por si só, não determina o fluxo ou as rotas a serem seguidos. Tampouco corrige eventuais imperfeições da arquitetura.

O usuário, suas características e a situação a que está exposto quando se utiliza das informações sinalizadas são premissas de sinalização. Já a 'linguagem' ou o estilo a serem adotados, bem como a especificação de materiais e técnicas de produção, podem ter na arquitetura o fio condutor para a concepção do projeto. Da arquitetura podemos retirar referências para criar o desenho das placas, suas proporções e localização, grafismos complementares, código cromático e outros elementos.

E cabe aqui uma ligeira digressão sobre o exato papel do designer em projetos de sinalização, especialmente em novas edificações. Por mais tentadora e confortável que seja a posição de prima donna que alguns assumem no cotidiano, neste caso estamos apenas na quinta fila do coro. E é fácil explicar em números. Um projeto de sinalização bem remunerado representa algo como $2 \%$ do total de recursos alocados para o conjunto de projetos. Cada caso é um caso, mas podemos afirmar que, usualmente, o conceito básico a ser seguido na concepção da sinalização é o de complementaridade à arquitetura e aos interiores. O que equivaleria ao glacê do bolo. Obviamente existem projetos em que a sinalização tem outra função - como cenografia, por exemplo. Mas esses são casos específicos e normalmente de caráter transitório. Não se trata simplesmente de nos transformarmos subitamente em YesMan seguindo à risca uma determinada linha ou tendência arquitetônica. Mas temos de admitir que outros são bem mais importantes no processo e têm mais poder de decisão e influência junto aos contratantes. O que temos de aprender nesses processos é saber ouvir.

\section{Sinalização e design corporativo}

Assim como a arquitetura segue (ou deveria seguir) um conceito síntese que determine a imagem desejada por uma instituição qualquer, a sinalização pode e deve contribuir para a consolidação da identidade corporativa de um shopping center, hospital ou campus universitário. O design do elemento suporte das informações, seu código cromático e tipográfico, sua diagramação e seu posicionamento no espaço podem contribuir para a fixação de alguns dos conceitos almejados na identidade corporativa.

No caso do campus Santo Amaro do Senac, partimos de um fragmento do elemento principal de sua identidade visual (uma elipse laranja inclinada) para determinar o desenho dos totens a serem utilizados na sinalização externa. Ao mesmo tempo utilizamos essa elipse como elemento organizador e unificador na sinalização interna.

Criamos uma paleta de cores para identificar os diversos edifícios e/ou alas internas do edifício acadêmico. Na sinalização externa, as dimensões e proporções dos totens foram determinadas de modo a se fundirem na paisagem do campus, sem competir com os edifícios e os passeios, ou mesmo sem encobri-los (ainda que parcialmente). Os totens com o nome dos edifícios são pintados em cores distintas predeterminadas, marcando os acessos. Já os totens direcionais, com as mesmas dimensões, mas com fundo verde (que se mescla ao paisagismo do campus), foram distribuídos em pontos previamente identificados de grande fluxo de usuários ou entroncamentos (para que lado vou?). Por causa da grande extensão do campus e das características dos edifícios (horizontais com grandes áreas), os totens foram desenhados em uma escala que possibilite sua leitura a pequena ou média distância (com 2 metros de altura). Ao mesmo tempo, suas cores, que identificam o tipo de totem, podem ser distinguidas a grandes distâncias. 


\section{Infodesıgn}

Todas essas características escolhidas para o projeto foram determinadas com base nos conceitos expressos na comunicação do Senac, o público específico do local - estudantes, funcionários e visitantes do campus - e sua identidade corporativa.

\section{Sinalização e legibilidade}

Criar pictogramas pode ser bem divertido. Quem nunca reparou nos inúmeros desenhos estampados em bares e restaurantes com o único objetivo de indicar os banheiros masculino e feminino? Para essa finalidade simples e direta, em que apenas duas opções de escolha são possíveis, a legibilidade de uma placa pode ser negligenciada em função de outros aspectos, como grafismos, integração com o projeto de interiores ou até mesmo uma sacada de humor. Mas essas são soluções específicas para aplicações ocasionais. Em projetos de sinalização,a legibilidade é uma preocupação constante, ainda que com maior ou menor intensidade.

A sinalização de rodovias é um bom exemplo. A leitura das placas deve ser imediata e precisa para que o condutor tenha tempo hábil de processar a informação e tomar uma decisão (por exemplo, reduzir a velocidade). Ainda neste exemplo a preocupação com a transmissão da informação é tamanha que se recorre à redundância para relembrar os motoristas constantemente: "saída a 1.000 m", "saída a 500 m" etc. Mas até mesmo em projetos nos quais a segurança não seja o principal aspecto, a legibilidade ainda é uma constante. Afinal, qual o propósito de se empenhar recursos para transmitir informações que não serão lidas ou que sejam desnecessárias?

A legibilidade é determinada por diversos aspectos e provavelmente irá determinar muitas das escolhas de design. O primeiro aspecto é a chamada qualidade do texto, o qual deve ser conciso e objetivo. Placa não é lugar de romance, ou pior, de enigmáticas poesias concretas. A prática nos ensinou que em textos de sinalização o único modo que realmente funciona é o imperativo: faça isso e não faça aquilo. Nada de 'talvez' ou 'quem sabe'. Suponha que existem três caminhos distintos de um determinado ponto $\mathrm{A}$ ao remoto ponto $\mathrm{B}$. Agora apenas imagine colocarmos essas três alternativas em uma única placa - rodoviária, por exemplo. Alguém será capaz de entender algo se estiver atrás de um volante a $100 \mathrm{~km} / \mathrm{h}$ ? Temos três informações que na verdade representam nenhuma.

Definido os textos, partimos para a tipografia na qual eles serão grafados: qual fonte será utilizada, com ou sem serifa, com quais corpos, espacejamentos etc. Mas para garantir que o texto seja lido não basta que se utilize uma fonte legível, em um corpo adequado para a distância a que se propõe sinalizar. O contraste entre o texto, a placa e os elementos que interferem na leitura, como reflexos de iluminação, pode comprometer um bom projeto. Voltando ao exemplo das rodovias, variantes como a velocidade dos veículos também devem ser consideradas no momento de escolher fontes, corpos e dimensões de placas.

Em alguns casos a legibilidade é levada ao extremo, como na sinalização de emergência, que conta com legislação própria e normas que determinam desde corpos mínimos de fontes até distâncias máximas entre a sinalização e o usuário, para garantir sua leitura e, conseqüentemente, sua segurança.

Atento a esses três pontos e dosando-os com bastante critério, você certamente atingirá a justa medida em seu projeto, respondendo não somente às necessidades do usuário, mas também aos seus desígnios e aos de seu cliente.

\section{Sobre os autores}

\section{Norberto "Lelé" Chamma}

Nasceu em São Paulo em 1948. Arquiteto formado pela Faculdade de Arquitetura e Urbanismo da Universidade de São Paulo (FAU-USP) em 1973. Sócio fundador do escritório Und Corporate Design, com atividades nas áreas de identidade corporativa e sinalização.

\section{Pedro Dominguez Pastorelo}

Nasceu em São Paulo em 1974. Arquiteto formado pela Faculdade de Arquitetura e Urbanismo da Universidade de São Paulo (FAU-USP) em 1998. Ingressou na Und Corporate Design em 1997. 